\title{
Difficulties in being responsible institutional investors: evidence from Malaysia
}

\author{
Hairul Azlan Annuar
}

\begin{abstract}
Purpose - The purpose of this paper is to ascertain whether institutional investors in Malaysia faced limitations when they are involved in the corporate governance of their investee companies.

Design/methodology/approach - A qualitative approach, consisting of a series of interviews with senior investment managers of different type of institutional investors, was chosen. In total, 18 interviews were conducted over a period of two months, which is thought to sufficiently provide the answers to the research purpose.

Findings - The interviews revealed there are difficulties in monitoring all investee companies due to lack of time and resources. Traditional measures such as company financial performance and dividend policy, continued to be favored and rigorously monitored. The overdependence on hard criteria may be a result of a culture of overly rewarding beneficiaries and a lack of expertise in being involved in specialized company areas such as strategy. Strict regulations hamper effort to be more involved in governing investee companies.

Research limitations/implications - The research used interviews and generalization may become an issue. In addition, access to many managers depended on recommendations, and the respondents are selected to represent the different types of institutional investors.

Originality/value - Investigation into factors that may limit institutional investors' involvement in corporate governance in Malaysian public listed companies, especially from a more qualitative viewpoint, is lacking. In addition, this paper advances the understanding of shareholder activism by adding to the literature by exploring the issue in a specific emerging markets context.
\end{abstract}

Keywords Malaysia, Interviews, Institutional investors, Corporate governance

Paper type Research paper

\section{Introduction}

Institutional investors in Malaysia are urged by policy prescription such as the Malaysian Code of Corporate Governance (MCCG) to play a more heightened role in the governing of their investee companies (Annuar, 2015). The MCCG recognized the importance of institutional investors taking a definite interest in the corporate governance matters of their investee companies such as on board composition and appointment of independent nonexecutive directors of necessary caliber and independence. The MCCG also emphasizes shareholders voting and one to one dialogue between companies and institutional investors as the means by which the institutions would be able to be involved in the corporate governance of the companies (Annuar, 2015). Although there are various means by which institutional investors can be involved in the governance of investee companies, research in developed countries has shown that there are limitations that they may face in becoming involved. David and Kochhar (1996) argue that institutional investors in the US and the UK face three types of barriers to effective governance, namely barriers from business
Hairul Azlan Annuar is based at the Department of Accounting, International Islamic University Malaysia, Kuala Lumpur, Malaysia.

Received 4 December 2017 Revised 6 April 2018

1 August 2018

23 January 2019

Accepted 18 February 2019 
relationships, regulatory environment, and information processing capabilities or limitations. Furthermore, Chaganti and Damanpour (1991) and Hansen and Hill (1991) state that institutional managers are reluctant to hold poorly performing shares for long due to the frequent evaluation of their performance that relates to the need to reward their beneficiaries. However, such analysis on the Malaysian environment has not been investigated as yet. An investigation into the limitations that may be faced by institutional investors in Malaysia is vital to understand and identify the factors that inhibit their participation.

In East Asian countries, including Malaysia, the corporate governance system is unique and is strongly influenced by culture. The system is often referred to as an insider model of corporate governance, with characteristics such as high concentration of ownership in a few hands and government ownership of publicly listed companies (Solomon and Solomon, 2004). Therefore, due to the involvement of the government in the ownership of Malaysian companies, the concern regarding the role of institutional investors is considered very significant. The Malaysian Government plays a leading role in ASEAN countries as the government-owned about 18 per cent of listed firms which represent roughly 35 per cent of market capitalization amounting to an average of RM250bn worth of investments on the Bursa Malaysia (Claessens et al., 2000). These investments are connected with strategic holdings in some of the nationalized firms and acquisition of shares in Bumiputra (indigenous Malay) quoted firms as part of the fall out of the 1997 East Asian financial crisis (The Edge Malaysia, 2003). Also, unlike the developed economies, there are vastly different types of institutional investors in Malaysia (Annuar, 2015). Institutional investors can be classified into two basic categories namely: governmental and financial institutions. While the former are institutions owned by the government by being the government's statutory bodies and agencies, the later consists of institutions majorly owned and control by financial intermediaries such as banks and insurance companies without government influences. Institutional investors having a link to the government are divided further into two categories. The first consists of large investment agencies that have been identified by the government as investment companies that allocate some or all of their funds to government-linked companies (GLCs), commonly referred to as government-linked investment companies (GLICs) (Putrajaya Committee, 2006). The other category is made up of government-linked investment agencies and foundations, and state corporations, which have not been identified as GLICs by the government and whose investments are much smaller in size as compared to the GLICs.

Annuar (2015) has shown that institutional investors in Malaysia support initiatives of the MCCG in involving institutional investors more in the governance of the companies invested. The study had revealed that involvement beyond the mere attendance at the annual general meetings, such as face-to-face communications, was being pursued. Nevertheless, problems or limitations that Malaysian institutional investors may be facing in these involvements were not elucidated. They may be facing similar issues faced by counterparts in other countries, which would limit their effectiveness in monitoring the investee companies. As such, the motivation of this research is derived from the fact that investigation into factors that may restrict institutional investors' involvement in corporate governance in Malaysian public listed companies, especially from a more qualitative viewpoint, is lacking. Also, this paper advances the understanding of shareholders activism by adding to the literature by exploring the issue in a specific emerging market context. It presents empirical evidence on the possible limitations facing Malaysian institutional investors in the governance of their investee companies. Due to the scarcity of literature of limitations of institutional investors' involvement in Malaysian companies, literature in developed countries are used as a point of reference and used as a basis of comparison for findings revealed by this study. Consequently, through the analysis, it may be concluded whether Malaysian institutional investors' faced similar problems or otherwise with the 
institutional investors of the developed economies. Accordingly, the study attempts to answer the following research question:

$R Q 1$. What are the factors that limit the role of institutional investors in corporate governance in Malaysia?

\section{Literature review}

Foremost among the theories applied in corporate governance research is agency theory, wherein its application is used in fields such as accounting, economics, finance, marketing, political science, organizational behavior and sociology (Eisenhardt, 1989). The theory evolved as a response to the changes in the way corporations are owned and controlled as a result of the development of the stock market (Solomon and Solomon, 2004). Entrepreneurs, who had set up companies, would gradually cede control to professional managers and shared ownership with many other shareholders when their companies became large (Mizruchi, 1983) and, consequently, listed entities. Ownership concentration has been acknowledged in the literature as an essential mechanism which control agency problems and improves investor protection (Shleifer and Vishny, 1997, Solomon and Solomon, 2004), as well as improving company performance (Agrawal and Knoeber, 1996; Chaganti and Damanpour, 1991), which Gillan and Starks (2000) argued would be to the benefit of all shareholders. According to this theory, institutional investors are theorized to actively monitor managerial behavior to safeguard their investments and discharge their fiduciary duties to their investors (David and Kochhar, 1996). Institutional investors are considered as one of the internal control mechanisms of a firm, apart from the firm's board of directors (Walsh and Seward, 1990).

There are divergent views, however, concerning the significance of institutional investors in ensuring sound corporate management. While some previous studies (Romano, 1993; Shleifer and Vishny, 1986) argue that institutional investors play a prominent internal control role within the organization in an attempt to check the management excessiveness, others (Ingley and van der Walt, 2004) believe that their capacity might be limited to the statutory voting at the annual general meetings.

Further, literature has identified certain limitations that could hinder the effectiveness of institutional investors (David and Kochhar, 1996; David et al., 1998; Gillan and Starks, 2000). Specifically, David and Kochhar (1996) suggest three fundamental limitations to sound enterprise governance by institutional investors. First, due to excessive regulations by the regulatory agencies on the ownership structure of the corporate entities by limiting the quantum of their equity stake. Second, the authors argue that due to the larger holding percentage, institutional investors might not be able to concurrently manage the information processing requirement and play vital internal control role. Thus, they usually focus only on the small proportion of their investments. Third, David and Kochhar (1996) identify that the inability to exercise influence on investee companies comes as a result of concurrent business relationships. Consequently, institutional investors may be reluctant to use their power as perceived in literature and stated in codes of corporate governance (David and Kochhar, 1996).

Gillan and Starks (2000) further argue that institutional investors cannot guide those charged with governance, as this would be outside of their primary function and expertise. Also, fund managers may be demotivated due to inadequate incentives to be involved in monitoring the internal affairs of business organizations. Also, as investors that have a residual interest in the entities, institutional investors may be overwhelmed and more focused on the financial performance of the investee companies. As a result, they would be more preoccupied in this aspect rather than in ineffective governance by management (Gillan and Starks, 2000; Graves, 1988; Zahra, 1996). 
After the East Asian crisis in 1997, the Malaysian Code on Corporate Governance (MCCG) was introduced, this among others places high expectations on institutional investors' involvement in corporate governance. Consistent with agency theory, MCCG recommends institutional investors' means of control are in the form of their investment criteria and through direct engagement with the investee companies. Research of institutional investors in Malaysia is insufficient. Some Malaysian studies and their findings include Osman (1988), Low et al. (1999), Rahman and Haniffa (2003) and Wahab et al. (2007), which provide evidence that the majority of investors in Malaysia, including institutional investors, depend upon financial analysis to evaluate stock performance. A study by Low and Seetharaman (2001) indicates that Malaysian institutional investors may also be interested in company strategy. They contend that these interests in the strategic arena are due to a perceived relationship between a successful company strategy and higher company performance. However, in the Malaysian context, apart from suggesting that institutional investors should also take into consideration corporate governance criteria, the literature review has not provided any indication that these matters are prioritized to the same extent as financial criteria and are consequently adopted as possible monitoring measures. The literature on Malaysia is also silent about any other possible limitations that may impair their heightened involvement in their investee companies.

\section{Methodology}

This paper aims to investigate and collect scientific evidence on the weak point concerning the participation of institutional investors in corporate governance among the listed firms following the introduction of MCCG in Malaysia. The primary source of data was employed to gather evidence and perceptions of the sampled respondents from institutional investors using interview protocols. The selected investors were considered following the objective of this study as explained earlier and the prior studies from developed economies such as the UK and the USA. A qualitative research approach was adopted, and a series of interviews were conducted among the senior managers of the sampled institutional investors. Structured interviews were conducted over a period of six weeks with a total number of 18 senior investments executive managers of institutional investors to generate data for the analyses.

However, based on the Malaysian economic environment, the study conducted interviews in line with an extract from three kinds of relevant institutions. Also, due to less sophistication level of the capital market in Malaysia as compared to developed economies, the 18 respondents are deemed to be sufficient for data generation. These include five senior officers from government-linked investment companies (GLIC) and three senior officers representing entities that have not been considered by the government to be GLIC otherwise termed as smaller government agencies (SGA) in this study. In addition, ten senior officers from non-government link companies (non-GLIC) consisting of four senior managers from insurance firms and six managers from the banking sector were selected. Eleven of the interviewees were introduced through recommendations[1].

The manager comprises 14 males and 4 females. While 2 of them declined to be tape recorded, 12 managers agreed to be put on tape after their permissions were sought. The interviewer, therefore, resulted in note taking from the two unrecorded interviews. The average years of experience of the respondent were 13.70 years, while the aggregate of their years of experience was 233 years. The years of experience justifies the generalization of findings of this study due to their ability to be authoritative in their positions as senior officers. Each interview lasted for about an hour on average, and responses were analyzed based on the cross-case method suggested by Miles and Huberman (1994) that combines case-oriented and variable-oriented types of analysis. The study employs a coding method to reduce the data, and themes were obtained by the deductive approach. Subsequently, the coded transcripts from the data were subjected to matrices analyses to form reliable 
conclusions. The next section presents the finding based on the theme adopted in the present study.

\section{Interview results}

As discussed in the literature review chapter, institutional investors may face certain limitations in being involved in the corporate governance of the companies and, consequently, in discharging their duties effectively. A few factors were identified that could limit institutional investors contribution. They are:

- regulations restricting ownership stakes (David and Kochhar, 1996);

- limitations in processing pertinent information due to vast holdings (David and Kochhar, 1996);

- having business relationships with investee companies (David and Kochhar, 1996);

- lack expertise to advise corporate management (Gillan and Starks, 2000); and

- short-term outlook concerning performance evaluation which is a consequent of the need to reward their beneficiaries with reasonable returns (Chaganti and Damanpour, 1991; Hansen and Hill, 1991).

The following section provides the results of the interviews on these issues.

\subsection{Regulations restricting ownership stakes}

The interviews revealed that due to the fallout caused by the East Asian crisis, regulations concerning investment especially by financial intermediaries such as banks and insurance companies had been shored up by the regulators. Limits were set as to the maximum amount of cash that can be invested either regarding the stock market as a whole or as per each company. Also, the option of heavy investing in the overseas markets is curtailed by a tight regulation that permits Malaysian institutions to invest only up to a certain small percentage of their total funds outside Malaysia. The upside to this regulatory intervention would be a more prudent and transparent investment process by the institutions (Annuar, 2015). However, the downside to the regulations means that it prevents banks and insurance companies from owning substantial stakes in investee companies which in turn do not motivate them enough to be directly involved in a company. A senior manager of a non-GLIC commented:

In Malaysia unit trust, banking and insurance guidelines stated that we are not allowed to invest in more than 5 per cent of the company stock. That prevents us from having a significant stake in a company. Hence, most of us would rather sell off rather than be involved. It is easier that way. If you are a small shareholder, you will incur low transaction costs when you sell off.

Another senior manager of a non-GLIC supported the above argument when he said:

\footnotetext{
There is a regulatory guideline given for the different class of assets of an insurance company. The limit for equities approved by the regulatory for insurance companies is 30 per cent, and for the Life business, it will touch close to that such as 25, 26 per cent of their total funds. It will be lower if the company runs both life and general business. That means we can only invest up to 30 per cent of the entire stock market, not in a single company. So how can we pressure the company when our holding is small? When there is a loss, what we normally do is to bite the bullet in the sense that we try to cut loss and whatever money we manage to recoup, we would invest it somewhere else.
}

This regulation concerning investment in local companies does not appear to be affecting GLICs and SGAs. SGAs' problem lies with the amount available for investment per se rather than the regulations affecting banks, insurance companies, and unit trusts companies. In 
contrast, GLICs, by having a larger number of members and contributors, and hence a larger amount of available investments as compared to SGAs, faced the problems of effectively managing their investments. The reason for this is that the Malaysian share market was considered to be small by the interviewees representing GLICs. Two of the interviewees from GLICs admitted that it is quite a challenge to invest in the small Malaysian stock market efficiently. For a large institutional investor, the amount of money available at its disposal and the limited opportunity to invest overseas has meant that it has limited avenues to place its funds in equity. GLICs may inadvertently place more funds in a company than what they had intended to, resulting in them becoming a substantial holder (Annuar, 2015). At the same time, large institutional investors would tend to avoid investing too much in a company that already has large investments from another institution on their books. A manager from a GLIC revealed that it is not common to have two or three large institutional investors in one company, each holding a substantial stake. Although by having some institutional investors with large investments in their books would give the companies more credibility, the negative side of it would be the absence of what is termed as a "free float," or in other words, the liquidity of the shares would be vastly diminished. Liquidity considerations would also mean that investing in small companies is not an immediate option either. The situation had compelled them to place more of their funds in fixed income and properties as a means of varying their investment options, apart from merely for safety reasons as discussed above.

The findings thus far provide strong support to David and Kochhar's (1996) contention regarding limited investment opportunities due to government regulations. However, in Malaysia, not all institutional investors faced this same problem. It appears that it is affecting the non-GLICs made up of banks and insurance companies. GLICs and SGAs though do not seem to be facing such an issue. GLICs especially face difficulty instead to efficiently manage their investment due to the smallness of the Malaysian market. Furthermore, there are indications from the GLIC, and SGA managers interviewed that certain investment decisions are directed from the top and which will usually be verified and agreed by the investment panels. An SGA senior manager exemplified:

Let me put it this way. Our investment panel is very independent, and we do have certain policies and guidelines in place. When there is a certain issue brought to us by the (ministry name), the panel will look at it, and if it finds that it is beneficial to the organization, in the long run, it won't say no. Most of the time if you were to get a letter which clearly states "ordered" they would still deliberate and evaluate. I can tell you, however, out of 10 that come from (name of authority), nine will be taken up.

The issuance of these directives has meant that some of the reasons for investing in longterm portfolios may not necessarily be strictly driven by market fundamentals. It may resemble a limitation in itself in that it limits the particular institution concerned from investing in other fundamentally well-managed companies. This finding also corroborates anecdotal arguments which had argued that governments in emerging markets do play an active interventionist role in the share market.

\subsection{Limitations in processing pertinent information due to vast holdings and need to reward their beneficiaries with reasonable returns}

Results of the interviews revealed unanimous agreement from all interviewees that investee companies' financial performance and dividend policy are essential factors in an investment making decision. This finding is consistent with research by Hill and Snell (1988), McConnell and Servaes (1990), Chaganti and Damanpour (1991) and Mehran (1995) that indicated financial performance as essential indicators to institutional investors as well as with other Malaysian studies by Osman (1988), Low et al. (1999), Rahman and Haniffa (2003) and Wahab et al. (2007). All interviewees agreed that there are a set of criteria that the investment panel of their organizations looks before making any investment decision. The 
panel or committee plays a very critical controlling role for the institutions, as they are the ones who will decide to what extent the institutions are exposed in every investee company. Information that is used as an input by the investment panel is compiled through reports supplied either internally by fund managers and research units, or externally through investment analysts and brokerage houses.

The interviews disclosed that the profitability of the company and previous years' track records represent the screening criteria mooted under the financial performance factor. In addition, financial performance ratios such as dividend yields, earnings per share and PE ratios were oft-quoted by the interviewees when the question of investment criteria was asked. The liquidity of the shares is another factor that is significantly linked with financial performance. A company that is profitable and possesses good financial records would normally be actively traded. As such, the institutions prefer these types of companies, as not only will the companies provide them with capital gain and yearly income, the institutions will not find it difficult to either buy or sell and buy back the shares when they want to. Consequently, the majority of interviewees stated that the bulk of their institutions' investment is directed towards big and long-established companies. A senior manager with a non-GLIC remarked:

If you look at the Malaysian market, there are a thousand over stocks in all the different markets, but the actively traded ones are probably not more than 30 stocks, and our strategy of investment would usually mirror this structure. So the philosophy here is to go mainly for highly capitalized stocks or big caps. We do have funds that focus on the small cap, but normally we would go for big caps, which are highly liquid and financially strong.

The interviews disclosed that the dominance of hard financial criteria in investment decision-making is because they are easier to comprehend and, as such, they help to save time and lower the prospect of ambiguity among the different levels of personnel involved in evaluating a particular counter. Moreover, although the evidence pointed to institutional investors being sophisticated investors, they do, however, face problems in deriving the necessary information to make investment decisions and to monitor all of the investee companies. Apart from the "heavyweight" counters that all fund managers are familiar with, they rely quite heavily on third-party research, primarily by external analysts from investment firms and brokerage houses with regards to other counters, which may inadvertently lead to over-dependence on financial criteria. Therefore, in other words, the institutions face a limited capability to perform complete monitoring on their own once they have invested in the companies. This finding supports the argument of David and Kochhar (1996) who state that institutional investors may still face limitations in processing pertinent information, as their holdings may be too extensive and spread across too many companies. A manager with a non- GLIC had this to say:

Overall, I don't think our fund managers they have got the time to inspect each company and interview each management that we have invested. Although the philosophy says that we should go to inspect every company, mainly it is based on the write-up, on market research.

\section{Another senior non-GLIC manager remarked:}

Internally we don't have the capability to monitor every single company. We don't do much primary research in the sense that we don't go up and talk to management on a regular basis. We rely a lot on local research coming from brokerage houses as well as on input from our contacts in the industry. Based on that input we can then evaluate and conclude.

Interestingly also from the interviews, there was an indication that, apart from a lack of time and resources, the fund managers' concentration on financial criteria and only on specific counters may be mainly due to the pressure to reward their investors with reasonable returns. This finding is consistent with Hansen and Hill (1991) who state that, due to this pressure, managers are more reluctant to hold poorly performing shares for long and risk 
further deterioration of the share prices and returns. Two interviewees from the GLICs provided evidence of it. The first one said:

The depositors expect a certain amount of return when they deposited with us. Last year we paid about 4.5 per cent bonus to them (the depositors). So definitely expectation is increasing, but we would try and manage as best as we can. Not just us, but most of the government agencies are looking for high dividend payout to sustain the returns to our members.

The second interviewee stated:

Profitability of our investee companies means a lot to us. It is because we are a performancebased company. You can see from our annual report the amount of dividends that we paid to our members last year [... ] that's right, 60 per cent dividend, which is very high by any standard.

Hence from the interviews, and unlike government regulation which affected non-GLICs only, all types of institutional investors in Malaysia faced the problems of having limited processing capabilities and the pressure of rewarding their beneficiaries leading to a focus on an exit strategy for investee companies having financial difficulties. This finding provides further evidence that institutional investors are not homogenous in that they may share the same problems on some issues while facing it alone on another matter. The interviews also disclosed that effective governance comes in many forms and expressions and one version of it is through the achievement of financial performance targets. Management would typically provide projections regarding financial performance, but when the results do not align with the forecast, it shows that there could be something wrong with the management and, consequently, the governance of the company. The interviews indicated that the institutions would accept the actual results and the explanations that accompany the publication of the results only for a specified period such as for one or two quarters. However, if the situation were to persist for several quarters, then the company might be seen to be misleading the investors, and this is often interpreted as bad governance on the part of the firm.

On the other hand, qualitative measurements such as corporate governance matters relating to the composition of the board of directors, directors' remuneration and nominations, although taken into consideration, did not appear as high up on the priority ladder of the institutions as the financial ones. Fifty-nine percent of participants mentioned that they had considered the board composition only after further prompting by the researcher. Furthermore, only 35 and 24 per cent of the interviewees agreed that they had looked into the directors' remuneration and nomination processes respectively. Although some of the institutions did check on the board composition, the remuneration of the directors and the directors' nomination policy, they did so in a simplistic manner as compared to the quantitative evaluation of the financial performance and strategy of a company. A senior manager of a non-GLIC remarked:

We do look into the track record and strength and weaknesses of the board and management, but not as intense as the financial record. It's very difficult to quantify these kinds of factors. Therefore these criteria are pinned back to the financial criterion, in terms of how healthy the balance sheet position of the company is.

The interviewees disclosed that, if the three areas fully comply with the recommendations of the MCCG and are conducted transparently, they would not have any problems investing with the companies. They believed that the presence of board committees, the separation between the role of CEOs and Chairman into two different individuals, performance-based remuneration, the statement of corporate governance in the annual report and the implementation of the MCCG on a blanket basis are all vital for the enhancement, expansion, and integrity of the share market. Furthermore, the participants were of the opinion that it is the role of regulators such as the Securities Commission (SC) to ensure that regulations concerning these areas fully comply. The interviewees often raised the issue of 
directors' independence, and they believed that it is the responsibility of the SC to endorse the independence of independent non-executive directors, once a company has declared a particular director as such. Consequently, this situation may discourage their active participation since they can always fall back upon others, especially the regulators, to intervene in the investee companies. A senior manager of a non-GLIC remarked:

We are merely parking our money in these companies to get a return, and we cannot be dwelling too much into company matters. I believe that this should be the responsibility of the securities commission and the Bursa Malaysia to ensure the nomination and remuneration process are transparent. They are the appropriate body to control all these structural requirements on behalf of investors. Corporate governance is more of a regulatory issue, and they should ensure that companies are professionally run.

Although a small number of interviewees did complain about the supervision and enforcement authority of the SC, the majority of the participants were of the opinion that the SC is performing its role as a regulator. Because the responsibility of ensuring board composition, directors' remuneration and the nomination are pushed back to the regulators, the main consideration when evaluating the people running a company is the reputation of the persons concerned, rather than board structure or procedures. The importance of having the right, trusted people on board, rather than structural considerations and board processes as indicated above, is supported by all of the interviewees. As such, many interviewees quoted the importance of having individuals with revered titles such as Tan Sri or Dato' on the board of a company, which ought to give an advantage to the firm regarding political mileage and networking.

The interviews further disclosed that necessary information regarding the directors and management would usually be found in the company annual reports or through dedicated financial services providers such as Bloomberg. For a company seeking a listing, the prospectus, which would have been verified by the SC, forms a vital source of information. Apart from information meant for public consumption, the institutions also source other background information that is not in the public domain through networks within the investment communities. The investment division of these institutions is headed by some personnel with years of experience who are highly capable of tracing the movement of individuals in corporate circles and the history of their business associations. The interviews disclosed that, through all these means, the institutions could compile and maintain a negative list containing names of individuals that these institutions should not associate themselves with regarding holding the shares of companies that appoint these individuals onto their boards.

\subsection{Lacking expertise and having a business relationship}

When interviewees were asked as to whether company strategy was an essential area in their investment criteria, all of them indicated that it was. However, the findings also showed that the manner in which they may be involved might not be construed as an active involvement. Apart from analysts' reports, the interviews disclosed that the institutions had visited the companies to discuss matters relating to strategy. However, their presence there was more focused on getting first-hand information on planned strategy or checking the progress of the current approach of the companies rather than intensely discussing or influencing the framework, content or direction of the strategy. It appears from the interviews that the institutions do not intend to meddle unnecessarily into areas in which they do not have the expertise. This finding gives support to Gillan and Starks (2000) who argue that institutional investors lack the knowledge to advise corporate management. This finding is also not consistent with the results of Hansen and Hill (1991) and Baysinger et al. (1991) who document institutional investors influence on company strategy. Regarding the lack of expertise, a senior manager with a non-GLIC remarked: 
We are just financial guys, and we won't know much about manufacturing or plantation, for instance. We may give inputs on what other companies we see are doing, but whether they want to listen or not, it is entirely up to them. On the other hand, some CEOs and EDs are egoistic, and they don't care about what you might be suggesting.

The interviews disclosed that the management makes a presentation concerning the business plans for the future and provides the institutions with a projection of what the earnings will be over the next few quarters or, in some circumstances, over the next two or three years. The interviews also revealed that it is crucial that the institutions understand the viability of the strategies and this is where they can query the management for further clarification.

Interviewees were also asked whether they would try to revise executive remuneration and affect the selection of board members through discussions with their investee companies. From the interviews, it can be gathered that non-GLICs and SGAs do not affect any revisions of executive remuneration during these private meetings. Similarly, participants from GLICs were of the same opinion. Although they may hold a substantial stake in a company or may have a director representative on board, directors' remuneration is purely left for the company to decide. A senior manager of a non-GLIC exemplified the views of the interviewees when he said:

The company visits are purely for business perspectives, to inquire about things such as what are the new projects in the pipeline or to analyze companies' performance. We don't go and ask, why your directors are paid these much? That is not a forum. Even at the AGM, it's quite difficult to ask such things. The thing is you can say little about this as, at the end of the day, the remuneration is an internal matter.

Despite executive remuneration being part of the management criteria in making investment decisions, the general feeling is that the executive remuneration is reasonable and hence is not closely monitored. The interviews disclosed that directors' remuneration in Malaysia is generally under control and it is not a big issue relative to the bottom line. The interviewees also believed that, if the management is doing a good job, they are entitled to be paid accordingly. In fact, surprisingly many of them believe that, relative to the achievements of the companies, many of the executives were underpaid.

With regards to the selection of board members, the interviews disclosed that non-GLICs and SGAs do not possess the power or the interest to affect the selection of board members. It is due to either insubstantial stock holdings, being more focused upon financial criteria or believing that the responsibility is upon the regulators to ensure the individuals appointed on board are of the right credentials. A senior manager of a non-GLIC remarked:

We could voice our opinions on directors who are or about to be nominated to the board, but most of the time we would abstain from doing that. If the financial performance is good, we normally do not care who is on board or who gets nominated.

Participants from non-GLICs were prompted as to whether their non-involvement in determining the board composition of their investee companies was, in part, a means to protect any business relationships that they may have with the companies. All were initially somewhat perplexed by the particular question. After further clarification from the researcher, they emphatically denied this association and stressed that their noninvolvement was due to them not being a significant shareholder. They further emphasized the professionalism attached to their investment making decisions, which is strictly based on investment criteria that are not linked to the business side of the association with their investee companies, if there happens to be one, which is handled by another division within their companies. This finding is not consistent with the scenario in the west, as depicted by and David and Kochhar (1996) and Brickley et al. (1988), where institutional investors do not exercise their ownership power when they have business relationships with the firms that they had invested. A senior manager of a non-GLIC remarked: 
The business side will take care of the business. The investment team will look at the value of the company before making any investments. The investment is totally an independent action, and there is no agreement to reciprocate.

Another senior manager of a non-GLIC explained:

When we invest in a unit trust or through investment banking, the asset manager is investing on behalf of the investors, using other people money and not his own money. So the banks do not directly have a vested interest in the company that they are investing in.

On the other hand, GLICs do affect the selection process, especially in situations where they are represented on the board by their holdings. GLICs may also influence the nomination process in cases when they are not on the board but have a substantial minority stake. Interviews with senior managers of GLICs revealed that the influence might occur when their interests may not be served, although these occasions are likely to be infrequent. Furthermore, GLICs invest in so many companies, and consequently, they are unable to send their representatives to sit on every board of the investee companies. Hence, they are likely to be selective in the types of companies in which they choose to be represented. Company representatives would not usually be sent to companies whose corporate governance is considered to be good. The interviews revealed that, if GLICs ever decide to send a representative to the board of these companies, it would be more for exposure to good governance. Finally, the interviews disclosed that it is possible that, in the future, the non-GLICs, primarily insurance companies, may find that their assets could reach a point whereby they need to invest a more considerable amount of funds in investee companies than their current stake. As such, when this happens, their abilities to influence executive remuneration and the nomination policy of their companies may reach the level which GLICs currently possess.

\section{Conclusion}

Using agency theory as the overarching theory that drives this research, the paper presents the findings of the interview survey with senior managers of Malaysian institutional investors. Institutional investors in Malaysia can be divided into those with a link to the government and those without, with the former further divided into large agencies termed as GLIC and smaller government agencies such as state corporations and foundations. A finding from the study which has a direct implication to the regulators in the Malaysian capital market relates to the monitoring of the governance structure and procedures in investee companies. The institutions had given and will continue to give priority to traditional measures such as company financial performance and dividend policy. Also, institutional investors of all types especially the GLICs do not have sufficient processing capabilities which could be due to time and manpower constraints. At the same time, they are also pressured to reward their beneficiaries by at the very least, maintaining the dividend amount paid out previously. These expectations further influence their over-dependencies on hard financial criteria. The interviewees representing the institutions also confided to the fact that they lack expertise and knowledge to be more involved in matters such as company strategy due to the diversity of the investee companies' industry. Furthermore, the interviews revealed another implication for practitioners. There exist several factors such as the nature of the Malaysian share market and rules and regulations concerning investment that may have inadvertently interfered with the process of the involvement and the attainment of the institutions' maturity. The positive aspect of setting the limit of investments for banks and insurance companies is to be prudent in safeguarding the banks and insurance companies' assets. However, this will inadvertently lead to small holdings that demotivate any form of active involvement in investee companies.

As a result, due to these issues, the institutions were less inclined towards qualitative corporate governance measures, such as board composition, the directors' nomination process and directors' remuneration policy as they believe it is the responsibility of the 
regulators, such as the SC, to nullify any drawbacks, if any. The institutions believe that it is not their responsibility to ensure that recommendations and best practices espoused by the MCCG are properly implemented in the companies they invest. Rather, it is the responsibility of the regulators. Hence, it appears that there is a mismatch in what the regulators expect regarding institutions' involvement and the institutions' actual interpretation of the involvement in the governance of the investee companies. As such, it would be advisable that the regulators and institutional investors were to meet and clarify the nature of involvement expected of the institutions and perhaps to discuss further in areas of collaborations among the two parties on the issue of monitoring.

In addition to practical implications, theoretical implications are affected as well. Agency theory had stated that institutional investors are a part of the internal monitoring mechanisms besides the independent directors. Hence, by pushing the responsibility back to the regulators, it means that the agency theory may not apply to the Malaysian institutional investors. At least not in the present situation. The interviews did reveal that the latter measures are now beginning to play a more significant part in GLICs evaluation criteria especially in companies in which they have a vast amount of investment targeted for the long term. Regarding the theoretical aspect of institutional investors, the study has shown to provide supporting evidence on the different types of institutional investor, which future research should identify before determining their influence on the various dimensions of corporate governance. In the case of Malaysia, it may be worthwhile to segregate institutional investors into those with or without links to the government. Separating them into long-and short-term investors may not be plausible, as institutions in Malaysia invest funds in both long and shortterm investments in varying proportions. Categorizing them into pressure resistant and pressure sensitive areas is not possible as well. In developed nations, pressure sensitive institutions are categorized as such due to the presence of a business relationship with the investee companies. In Malaysia, however, non-GLICs do not currently face these problems, due to the fact they hold lower stakes in the companies as compared to their counterparts in developed nations, which may not affect any business relationship that they may have. Also, from the interviews, business and investment activities are taken by different entities of the banks and insurance companies. GLICs' investment aims include the broader objectives of nation-building and socially responsible initiatives related to the native Malays (Bumiputra), which would promote a greater role in the governance of their investee companies. Thus, to avoid more confusion regarding the categorization of an institutional investor in Malaysia, it is suggested that the classification is based on the appearance of a linkage with the government, i.e. GLICs vs non-GLICs. Notwithstanding this, however, this paper provides support to the notion that institutional investors are not a homogenous group of the investor.

Finally, the interview analysis did reveal that the GLICs, with the shareholder power they possess, could be a significant participant which could change the face of institutional investor' involvement in the future. There are also indications from the interview data that non-GLICs from the insurance industry may experience the same situation as the GLICs in the future, whereby their insurance funds could grow to the extent that they too would need to be more involved in the governance and performance of their investee companies.

Admittedly, there are several limitations present which is recognized and discussed below. First, the study draws upon the Malaysian Code of Corporate Governance (MCGC) as the basis of the interviews, analysis and discussions. However in Malaysia, apart from MCCG, there is another code drafted explicitly for the institutional investors, namely the Malaysian Code for Institutional Investors (MCII). Future studies are henceforth strongly advised to include the MCII in any research about institutional investors in Malaysia. Second, this study seeks the perceptions of only the senior managers of the institutions. Future research may examine the opinions of other groups that are connected to the corporate governance system such as the regulators in the form of SC, the Malaysian bourse known as Bursa Malaysia, as well as representatives for the minority shareholders, namely, the Minority Shareholders 
Watchdog Group. Opinions from academicians, foreign institutional investors, international and local analysts, representatives of foreign companies listed on Bursa Malaysia, politicians and government policymakers should also be sought. These would allow more data to be analyzed and cross-referenced to strengthen the findings. Finally, conclusions of this study suggest that future studies concerning aspects of management and business in Malaysia in particular, or Asia in general, should not dismiss and underestimate the underlying influence of culture. Further research should be explicitly aimed at examining the impact of national and cross-culture on the culture of the organizations. In furtherance of that, this study could be extended to include other countries in the Asian region, most notably Malaysia's closest neighbors such as Thailand, Singapore and Indonesia. All these countries, to a varying extent, suffered in the East Asian crisis, and have taken steps to strengthen their respective corporate governance systems. The extension of this study into these other countries would ascertain their practices regarding the involvement of institutional investors, which might be influenced by individual national factors.

\section{Note}

1. The recommendations came from various sources such as acquaintances and families of the managers as well as the snowball effect.

\section{References}

Agrawal, A. and Knoeber, C.R. (1996), "Firm performance and mechanisms to control agency problems between managers and shareholders", Journal of Financial and Quantitative Analysis, Vol. 31 No. 3, pp. 377-397.

Annuar, H.A. (2015), "Changes in ownership forms and role of institutional investors in governing public companies in Malaysia", Journal of Accounting \& Organizational Change, Vol. 11 No. 4, pp. 455-475

Brickley, J.A., Lease, R.C. and Smith, C.W. (1988), "Ownership structure and voting on antitakeover amendments", Journal of Financial Economics, Vol. 20, pp. 267-291.

Chaganti, R. and Damanpour, F. (1991), "Institutional ownership, Capital structure, and firm performance", Strategic Management Journal, Vol. 12 No. 7, pp. 479-471.

Claessens, S., Djankov, S. and Lang, L. (2000), "The separation of ownership and control in East Asian corporations", Journal of Financial Economics, Vol. 58 Nos 1/2, pp. 81-112.

David, P. and Kochhar, R. (1996), "Barriers to effective corporate governance by institutional investors: implications for theory and practice", European Management Journal, Vol. 14 No. 5, pp. 457-466.

David, P., Kochhar, R. and Levitas, E. (1998), "The effect of institutional investors on the level and mix of CEO compensation", Academy of Management Journal, Vol. 41 No. 2, pp. 200-208.

Eisenhardt, K.M. (1989), "Agency theory: an assessment and review", Academy of Management Review, Vol. 14 No. 1, pp. 57-74.

Gillan, S.L. and Starks, L.T. (2000), "Corporate governance proposals and shareholder activism: the role of institutional investors", Journal of Financial Economics, Vol. 57 No. 2, pp. 275-305.

Graves, S.B. (1988), "Institutional ownership and corporate R\&D in the computer industry", Academy of Management Journal, Vol. 31, pp. 417-428.

Hansen, G.S. and Hill, C.W.L. (1991), "Are institutional investors myopic? A Time-Series study of four Technology-Driven industries”, Strategic Management Journal, Vol. 12 No. 1, pp. 1-16.

Hill, C.W.L. and Snell, S.A. (1988), "External control, corporate strategy, and firm performance in Research-Intensive industries", Strategic Management Journal, Vol. 9 No. 6, pp. 577-590.

Ingley, C.B. and Van der Walt, N.T. (2004), "Corporate governance, institutional investors and conflicts of interest”, Corporate Governance International Review, Vol. 12 No. 4, pp. 534-551.

Low, K.L.T. and Seetharaman, A. (2001), The Sustainability of Business Corporate Governance: Evidence from the Malaysia Public-Listed Companies, British Accounting Association Special Interest Group on Corporate Governance, available at: http://ssrn.com/abstract=294577 
Low, K.L.T., Lai, M.M. and Yap, V.C. (1999), "A case study of institutional measures to counteract the financial crisis in Malaysia", Paper presented at the Eighth Conference on the Theories and Practices of Security and Financial Markets, Taiwan, 11-12 December.

McConnell, J.J. and Servaes, H. (1990), "Additional evidence on equity ownership and corporate value", Journal of Financial Economics, Vol. 27 No. 2, pp. 595-612.

Mehran, H. (1995), "Executive compensation, ownership, and firm performance", Journal of Financial Economics, Vol. 38 No. 2, pp. 163-184.

Miles, M. and Huberman, M. (1994), Qualitative Data Analysis, Sage Publications, Beverly Hills.

Mizruchi, M.S. (1983), "Who controls whom? An examination of the relation between management and boards of directors in large American corporations", Academy of Management Review, Vol. 8 No. 3, pp. 426-435.

Osman, M.Z. (1988), "The study of the extent of knowledge and usage of investment technique on the KLSE individual investors", Journal of Management, Vol. 6/7, pp. 21-34.

Putrajaya Committee (2006), Catalysing GLC Transformation to Advance Malaysia's Development, Government Printer, Putrajaya.

Rahman, R.A. and Haniffa, R. (2003), "Internal governance mechanisms and performance of Malaysian listed companies", ANZAM 2003 Conference, 2-4 December, Perth.

Romano, R. (1993), "Public pension fund activism in corporate governance reconsidered", Columbia Law Review, Vol. 93 No. 4, pp. 795-853.

Shleifer, A. and Vishny, R.W. (1986), "Large shareholders and corporate control", Journal of Political Economy, Vol. 94 No. 3, , pp. 461-488.

Solomon, J. and Solomon, A. (2004), Corporate Governance and Accountability, John Wiley \& Sons, West Sussex.

The Edge Malaysia (2003), Government Stakes in the Top 30 Listed Firms, The Edge Malaysia, Kuala Lumpur.

Wahab, E.A.A., How, J.C.Y. and Verhoeven, P. (2007), "The impact of the Malaysian code on corporate governance: compliance, institutional investors and stock performance", Journal of Contemporary Accounting, Vol. 3 No. 2, pp. 106-129.

Walsh, J.P. and Seward, J.K. (1990), "On the efficiency of internal and external corporate control mechanisms", Academy of Management Review, Vol. 15 No. 3, pp. 421-458.

Zahra, S.A. (1996), "Governance, ownership, and corporate entrepreneurship: the moderating impact of industry technological opportunities", Academy of Management Journal, Vol. 39 No. 6, pp. 1713-1735.

\section{Further reading}

Graves, S.B. and Waddock, S.A. (1990), "Institutional owners and corporate social performance", Academy of Management Journal, Vol. 37 No. 4, pp. 1034-1046.

Kochhar, R. and David, P. (1996), "Institutional investors and firm innovation: a test of competing hypotheses", Strategic Management Journal, Vol. 17 No. 1, pp. 73-84.

Zahra, S.A., Neubaum, D.O. and Huse, M. (2000), "Entrepreneurship in Medium-Size companies: exploring the effects of ownership and governance systems", Journal of Management, Vol. 26 No. 5, pp. 947-976.

\section{Corresponding author}

Hairul Azlan Annuar can be contacted at: hazalan@iium.edu.my

For instructions on how to order reprints of this article, please visit our website: www.emeraldgrouppublishing.com/licensing/reprints.htm

Or contact us for further details: permissions@emeraldinsight.com 